\title{
NDP Kinase 7 Is a Conserved Microtubule-Binding Protein Preferentially Expressed in Ciliated Cells
}

\author{
Takashi Ikeda* \\ Department of Biological Sciences, Graduate School of Science, University of Tokyo, Hongo, Bunkyo-ku, \\ Tokyo 113-0033, Japan
}

\begin{abstract}
Nucleoside diphosphate (NDP) kinase is an enzyme that synthesizes the nucleoside triphosphates. In mammals, nine sequences (NDK1-NDK9) have been found with domain(s) homologous to the catalytic domain of NDP kinase, and some of them have been shown to associate with sperm flagella. The present study examines the localization of NDK7, for which little information has been available. Database analysis showed that the NDK7 gene is present in organisms with cilia and flagella. Western blotting analyses of various mouse tissues consistently indicated that NDK7 is preferentially expressed in tissues with motile cilia as well as in sperm. Immunofluorescence microscopy revealed that this protein is localized along the entire length of the TritonX-100insoluble fraction of sperm flagella, possibly in the axonemes. Unexpectedly, however, NDK7 in tracheal epithelia was found in the cell body but not in cilia. Finally, in vitro co-sedimentation assays using recombinant proteins showed that both mouse and Chlamydomonas NDK7 directly bind to microtubules.
\end{abstract}

Key words: flagella/cilia/nme7/nm23-H7/DM10 domain

\section{Introduction}

Cilia and flagella play vital roles in a wide range of eukaryotes. These organelles are essential for unicellular organisms and sperm to swim. Cilia are important for vertebrates in determining the left-right body asymmetry during development (Nonaka et al., 1998), as well as in producing fluid flow over the surface of various organs such as the cerebral ventricle, trachea, lung, and oviduct in adult animals. The axoneme of cilia and flagella has a highly conserved microtubule-based structure. Microtubules are constructed through tubulin polymerization, a process that is accompanied by GTP hydrolysis. In motile axonemes, dynein molecules provide the driving force using the energy derived from ATP hydrolysis. Thus, rapid local recycling of nucleoside triphosphates (NTPs) is required for the generation of axonemal structure and movement. To fulfill this requirement, cilia and flagella are equipped with means to supply NTPs.

\footnotetext{
*To whom correspondence should be addressed: Takashi Ikeda, Department of Biological Sciences, Graduate School of Science, University of Tokyo, Hongo, Bunkyo-ku, Tokyo 113-0033, Japan.

Tel/Fax: +81-42-739-8453

E-mail: tikeda@lab.tamagawa.ac.jp

Present address: Tamagawa University Brain Science Institute, Machida, Tokyo 194-8610, Japan.
}

Nucleoside diphosphate (NDP) kinase is one of the enzymes that functions for such a purpose. This enzyme synthesizes NTPs (e.g., ATP) from NDPs (e.g., ADP). In mammals, nine proteins that contain domain(s) homologous to the enzymatic domain of NDP kinase have been identified (called NDK1-9, nm23-H1-9, or nme1-9) (Lacombe et al., 2000; Sadek et al., 2003; Boissan et al., 2009) (Table I). They can be phylogenetically classified into two groups (group I and II) (Lacombe et al., 2000; Sadek et al., 2003; Boissan et al., 2009). All members of group I enzymes (NDK1 to 4) share high amino-acid sequence identity with each other. None of them contains any other known functional domains. Group I enzymes are expressed ubiquitously (Lacombe et al., 2000) and involved in a wide variety of cellular processes that include suppression of tumor metastasis (Steeg et al., 1988; Chang et al., 1994; Leone et al., 1991; MacDonald et al., 1996), transcription regulation (Postel et al., 2000), DNA cleavage (Postel et al., 2000; Ma et al., 2002; Ma et al., 2004; Yoon et al., 2005) and p53induced apoptosis (Tsuiki et al., 1999). Some NDP kinases have been abundantly found in specific locations of postmeiotic male germ cells and in mature sperm flagella, suggesting that they are involved in spermiogenesis or sperm motility (Munier et al., 2003).

In contrast to group I, group II proteins (NDK5-9) are divergent in the amino acid sequence within the group. All 
Table I. MAMMALIAN NUCLEOSIDE DIPHOSPHATE KINASES

\begin{tabular}{|c|c|c|c|c|c|c|c|}
\hline & Group & Domain composition & Conservation & Expression & $\begin{array}{l}\text { Localization in } \\
\text { sperm flagella }\end{array}$ & $\begin{array}{l}\text { Other ciliated } \\
\text { tissues }\end{array}$ & $\begin{array}{l}\text { Direct association } \\
\text { with microtubules }\end{array}$ \\
\hline NDK1 & I & NDK & Yes & ${ }^{1}$ Ubiquitous & ${ }^{2} \mathrm{Yes}$ & - & - \\
\hline NDK2 & I & NDK & Yes & ${ }^{1}$ Ubiquitous & ${ }^{2} \mathrm{Yes}$ & - & - \\
\hline NDK3 & I & NDK & Yes & ${ }^{1}$ Ubiquitous & ${ }^{2} \mathrm{No}$ & - & - \\
\hline NDK4 & I & NDK & Yes & $\begin{array}{l}\text { 'Ubiquitous } \\
\text { (Mitochondria) }\end{array}$ & ${ }^{2} \mathrm{No}$ & - & - \\
\hline NDK5 & II & NDK-Dpy30 & $\begin{array}{l}\text { From protists to } \\
\text { mammals with cilia/ } \\
\text { flagella }\end{array}$ & ${ }^{1}$ Mainly testis & ${ }^{2} \mathrm{Yes}$ & - & - \\
\hline NDK6 & II & NDK & $\begin{array}{l}\text { Wide range of } \\
\text { multicellular organisms } \\
\text { with cilia/flagella }\end{array}$ & $\begin{array}{l}\text { 'Ubiquitous } \\
\text { (Cytoplasm and } \\
\text { mitochondria) }\end{array}$ & - & - & - \\
\hline NDK7 & II & DM10-NDK-NDK & This study & This study & This study & This study & This study \\
\hline NDK8 & II & Trx-NDK-NDK-NDK & $\begin{array}{l}\text { Wide range of } \\
\text { multicellular organisms } \\
\text { with cilia/flagella } \\
\text { (not found in insects) }\end{array}$ & $\begin{array}{l}{ }^{3} \text { Mainly testis } \\
\left({ }^{4} \text { Weakly trachea and }\right. \\
\text { nasal cells) }\end{array}$ & ${ }^{3}$ Yes & - & ${ }^{4}$ Yes \\
\hline NDK9 & II & Trx-NDK & $\begin{array}{l}\text { Wide range of } \\
\text { multicellular organisms } \\
\text { with cilia/flagella } \\
\text { (not found in insects) }\end{array}$ & $\begin{array}{l}\text { 5Mainly testis and lung } \\
\text { (Weakly ubiquitous) }\end{array}$ & ${ }^{5}$ Yes & $\begin{array}{l}\text { 5Cilia of } \\
\text { lung epithelia }\end{array}$ & ${ }^{5} \mathrm{Yes}$ \\
\hline
\end{tabular}

Trx, thioredoxin domain. 'Lacombe et al. (2000), ${ }^{2}$ Munier et al. (2003), ${ }^{3}$ Sadek et al. (2001); Miranda-Vizuete et al. (2003), ${ }^{4}$ Duriez et al. (2007), ${ }^{5}$ Sadek et al. (2003).

members except NDK6, a mitochondrial NDP kinase, contain other functional domain(s) (Lacombe et al., 2000; Yoon et al., 2005; Boissan et al., 2009). They are thought to be expressed predominantly in testis (Lacombe et al., 2000; Sadek et al., 2003) and NDK5, 8 (also named Sptrx-2; Sadek et al., 2001) and 9 (also named Txl-2; Sadek et al., 2003) are known to localize to the sperm flagella. An NDK5 homologue is identified in Chlamydomonas flagella, suggesting that it is a conserved flagellar protein (Patel-King et al., 2004). NDK8 and 9 are not conserved in lower organisms such as Chlamydomonas, but they are associated also with respiratory and lung cilia. A first step to understanding the specific role of each NDK in cilia and flagella would be to clarify its expression and localization. However, while various NDP kinases have been reasonably well characterized, little information is available about NDK7 except that Patel-King et al. (2004) surmised that this protein is tightly associated with the axoneme. They showed that Western blot analyses using an anti-Chlamydomonas NDK5 (p61) antibody detected an approximately $40 \mathrm{kDa}$ axonemal protein (p40) in addition to NDK5 and, from its size, suggested that it might be Chlamydomonas NDK7. However, whether NDK7 is actually associated with axonemes and, if so, whether the association is common among ciliated tissues and species remain to be clarified. The present study examined the expression and localization of this protein.

\section{Materials and Methods}

\section{Animals and cells}

Sexually mature ICR strain mice were purchased from CLEA Japan, Inc. (Tokyo, Japan). Wild-type (137c) and cw92 (a cell wall-deficient strain) strain $C$. reinhardtii were cultured in Tris acetate/phosphate (TAP) medium (Gorman and Levine, 1965) on a $12 \mathrm{~h} / 12 \mathrm{~h} \mathrm{light} / \mathrm{dark}$ cycle at $25^{\circ} \mathrm{C}$. Flagellar axonemes of Chlamydomonas were isolated according to Witman et al. (1972).

\section{Preparation of murine spermatozoa and tracheal epithelial cells}

Spermatozoa were obtained by squeezing the dissected epididymis (Hoppe, 1975). Tracheal epithelial cells were obtained by scraping the inner surface of the trachea with a scalpel. The cells were collected by centrifugation.

\section{Expression and purification of recombinant NDK7 proteins}

Recombinant NDK7 proteins were expressed using the Bac-to-Bac Baculovirus Expression System (Invitrogen, Carlsbad, CA). Total RNA was prepared from mouse testis and wild-type C. reinhardtii cells using TRIzol Reagent (Invitrogen, Carlsbad, CA) and first strand cDNAs were synthesized by SuperScript II reverse transcriptase (Invitrogen, Carlsbad, CA) using an oligo(dT) $)_{12-18}$ primer. Using them as templates, cDNAs encoding the full-length coding 
sequences of mouse and Chlamydomonas NDK7 were amplified by polymerase chain reaction (PCR) using the primer sets, mnm23-H7_BamHI_F [5'-CGC GGA TCC ATG AGA GCC TGT CAG CAG-3'] and nm23-H7+6His_KpnI_R [5'-CGG GGT ACC TAG TGA TGG TGA TGG TGA TGA TTA TCC AAG ATC TTG AAG-3'], and cnm23-H7_BamHI_F [5'-CGC GGA TCC ATG TCC GTG GAT GAA TTC-3'] and cnm23-H7+6His KpnI_R [5'-CGG GGT ACC TAG TGA TGG TGA TGG TGA TGC GAC GCG GTG GGC AGG ATG-3']. The PCR products were ligated into pFastBacl vector (Invitrogen, Carlsbad, CA). Production and purification of the recombinant proteins were followed by Ikeda (2008). Briefly, baculoviruses expressing $6 \times$ Histagged NDK7 proteins were produced according to manufacturer's recommendations. Sf9 insect cells (Invitrogen, Carlsbad, CA) infected with the viruses were lysed in a lysis buffer $(0.6 \mathrm{M} \mathrm{NaCl}$, $50 \mathrm{mM} \mathrm{NaH}{ }_{2} \mathrm{PO}_{4}, 10 \mathrm{mM}$ imidazole, $0.1 \%$ TritonX-100) and the NDK7 recombinants fused to $6 \times$ His-tag were primarily purified using Ni-NTA Agarose (Qiagen, Valencia, CA). Subsequently, these solutions were fractionated by gel filtration using Superdex 200 PC 3.2/30 column (GE Healthcare UK Ltd., Buckinghamshire, UK) in SMART System (GE Healthcare UK Ltd., Buckinghamshire, UK) and the fractions containing pure NDK7 proteins were collected. These proteins were used as the antigens for antibody production (see below) or dialyzed against a tubulin assembly

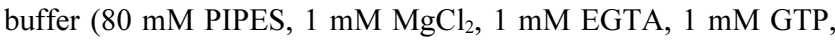
$\mathrm{pH}$ 6.8) for microtubule co-sedimentation assays (see below).

\section{Antibody production}

Extensively purified recombinant mouse and Chlamydomonas NDK7 (see above) were separated by SDS-PAGE and the corresponding bands were cut out. They were dialyzed against phosphatebuffered saline (PBS; $137 \mathrm{mM} \mathrm{NaCl}, 8.1 \mathrm{mM} \mathrm{Na}_{2} \mathrm{HPO}_{4}, 2.68 \mathrm{mM}$ $\left.\mathrm{KCl}, 1.47 \mathrm{mM} \mathrm{KH}_{2} \mathrm{PO}_{4}, \mathrm{pH} 7.5\right)$ and used as the antigens to immunize rabbits. The antibodies were purified from the sera by a blotpurification method (Olmsted, 1981) using the recombinant antigens.

\section{Western blot analyses}

Mouse tissues, except for sperm, were homogenized in a lysis buffer ( $5 \mathrm{M}$ urea, $2 \mathrm{M}$ thiourea, $0.5 \%$ TritonX-100) and centrifuged. The supernatants were collected and the protein concentrations were determined. After being adjusted to the identical concentration, the protein solutions were mixed with a $2 \times$ SDSPAGE sample buffer $(100 \mathrm{mM}$ Tris- $\mathrm{HCl}, 4 \%$ SDS, $12 \% \beta-$ mercaptoethanol, $24 \%$ glycerol, $0.05 \%$ bromophenol blue, $\mathrm{pH}$ 6.8). Samples of the same volume were subjected to SDS-PAGE. Mouse sperm and Chlamydomonas flagellar axonemes were lysed with the $1 \times$ SDS-PAGE sample buffer. Western blot procedures were modified from Towbin et al. (1979). Immunoreacted bands were detected using an alkaline phosphatase-conjugated, affinitypurified goat anti-rabbit IgG antibody (Sigma, St. Louis, MO) and BCIP/NBT Membrane Phosphatase Substrate System (KPL, Gaithersburg, MD).

\section{Indirect immunofluorescence observations}

Indirect immunofluorescence experiments of mouse spermatozoa and tracheal epithelial cells were performed as previously described (Ikeda et al., 2005). These tissues were incubated with the affinity-purified anti-mouse NDK7 antiserum and an antiacetylated $\alpha$-tubulin antibody (monoclonal 6-11B-1; SigmaAldrich; Piperno and Fuller, 1985). Subsequently, these samples were incubated with Cy3-conjugated sheep anti-rabbit IgG (Jackson ImmunoResearch Laboratories, Inc., West Grove, PA) and FITC-conjugated goat anti-mouse IgG (Sigma-Aldrich). Specimens were observed with an Axioplan microscope (Zeiss, Oberkochen, Germany).

\section{Preparation of PC-tubulin and in vitro synthesis of microtubules}

Purified $\alpha / \beta$-tubulin heterodimer (PC-tubulin) was obtained from porcine brain by cycles of temperature-dependent polymerization and phosphocellulose chromatography (Shelanski et al., 1973). PC-tubulin was polymerized by incubation at $37^{\circ} \mathrm{C}$ in a tubulin assembly buffer ( $80 \mathrm{mM}$ PIPES, $1 \mathrm{mM} \mathrm{MgCl} 2,1 \mathrm{mM}$ EGTA, 1 $\mathrm{mM}$ GTP, $\mathrm{pH}$ 6.8) containing 20\% (v/v) dimethyl sulfoxide (DMSO). Microtubules were stabilized by addition of $20 \mu \mathrm{M}$ taxol and collected by centrifugation at $30^{\circ} \mathrm{C}$. The precipitated microtubules were washed with the tubulin assembly buffer containing $20 \mu \mathrm{M}$ taxol and resuspended in an appropriate volume of the buffer.

\section{Microtubule co-sedimentation assays}

The recombinant NDK7 proteins were mixed with stabilized microtubules in the tubulin assembly buffer containing $0.1 \%$ Triton $\mathrm{X}-100$ and $20 \mu \mathrm{M}$ taxol. After incubation at $37^{\circ} \mathrm{C}$, microtubules were collected by centrifugation and washed with the buffer. Both the precipitates and the supernatants were analyzed by SDS-PAGE. The presence of the recombinant NDK7 proteins were detected by staining with Coomassie brilliant blue (CBB).

\section{Quantification of NDK7-microtubule Interactions}

Various amounts of mouse NDK7 recombinants were mixed with a constant amount of microtubules. NDK7 molecules bound and unbound to microtubules were separated by centrifugation and analyzed by SDS-PAGE. The amounts of NDK7 in both fractions were estimated by densitometry of the CBB-stained SDS-PAGE gel using a CS Analyzer (ATTO, Tokyo, Japan).

\section{Results}

\section{NDK7-like sequences are conserved in a wide range of eukaryotes with motile axonemes}

A BLAST search using the amino acid sequence of human NDK7 (GenBank Accession No. NP_037462) as the query 
a

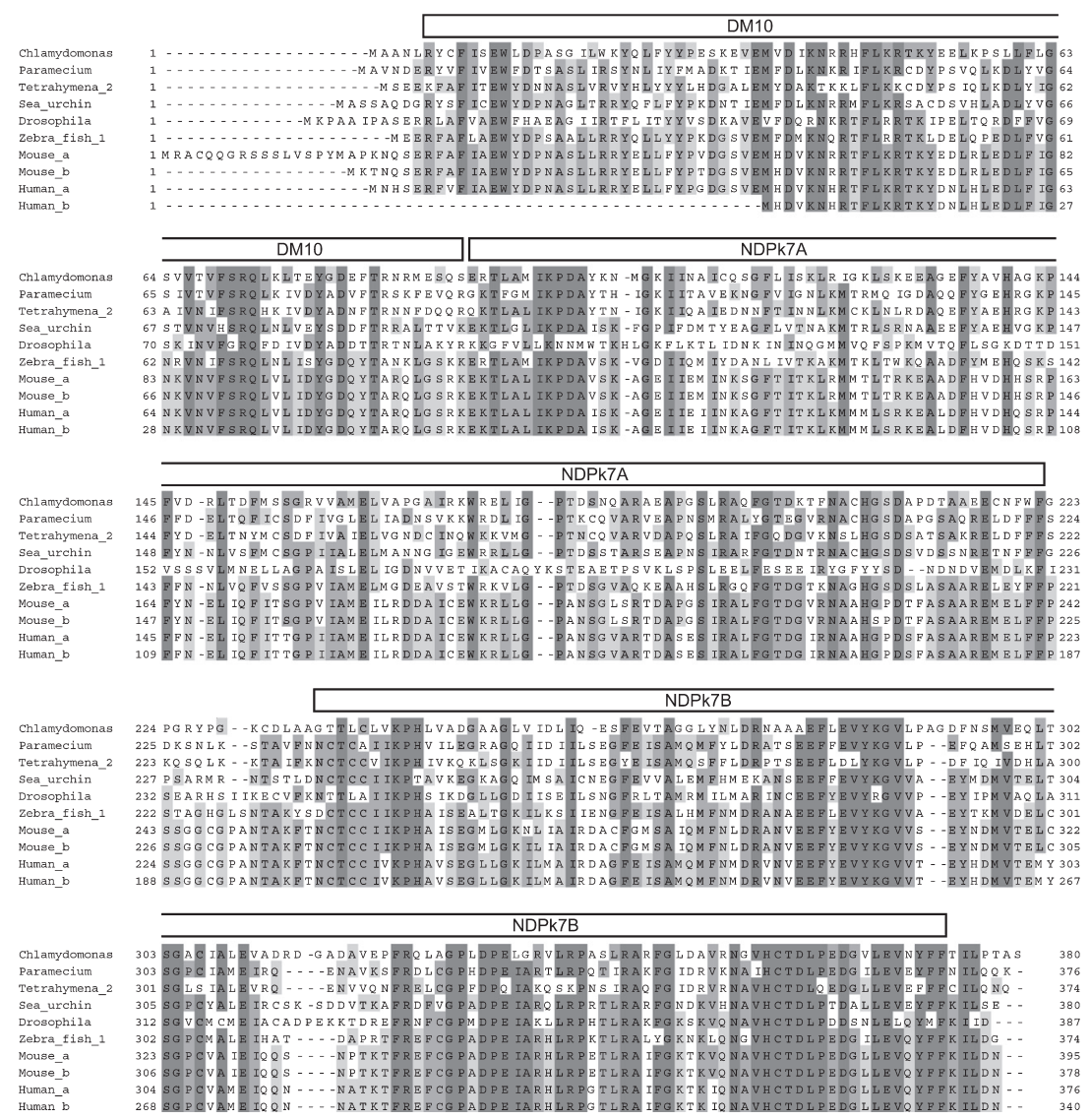

b

Tetrahymena thermophila_1 (2,005 amino acids)

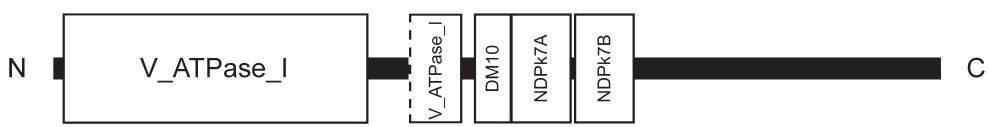

Danio rerio_2 (418 amino acids)

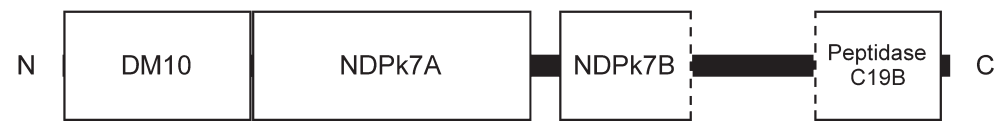

Fig. 1. NDK7 is conserved in a wide range of eukaryotes with motile axonemes. (a) Alignment of NDK7 amino acid sequences of various organisms. NDK7-like amino acid sequences were obtained from C. reinhardtii (GenBank Accession No. XP_001702841), Paramecium tetraurelia (XP 001425784), Tetrahymena thermophila (XP_001015884), Drosophila melanogaster (NP_649926), Danio rerio (CAI21297, XP_686692), Mus musculus (NP_612187, AAH38021) and Homo sapiens (NP 037462, NP 932076). Alignment was created using CLUSTALW ver. 1.83 (Thompson et al., 1994). Highly conserved residues are highlighted in dark gray, and residues conserved in the majority of sequences are highlighted in light gray. All the sequences have a similar functional domain composition, a DM10 domain with unknown function followed by two NDP kinase domains. (b) Functional domain compositions of NDK7-like sequences of Tetrahymena isoform 1 and zebra fish isoform 2. Tetrahymena isoform 1 (XP_001009581) contains a V-type ATPase $116 \mathrm{kDa}$ subunit family domain (V_ATPase_I) at the N-terminus to an NDK7-like region (DM10-NDPk7A-NDPk7B). Zebra fish isoform 2 (XP_686692) contains a truncated Peptidase C19B domain at the C-terminus to an NDK7-like region. Dotted lines indicate truncations of the domain. Domain structures were analyzed using blastp 2.2.17.

showed that NDK7-like amino acid sequences are present in various organisms with motile axonemes from protists to mammals. In Chlamydomonas, it is registered as FAP67 (flagellar associated protein 67) (Pazour et al., 2005) (Fig. 1a). No sequence homologous to NDK7 was found in organisms without cilia or flagella and in Caenorhabditis 


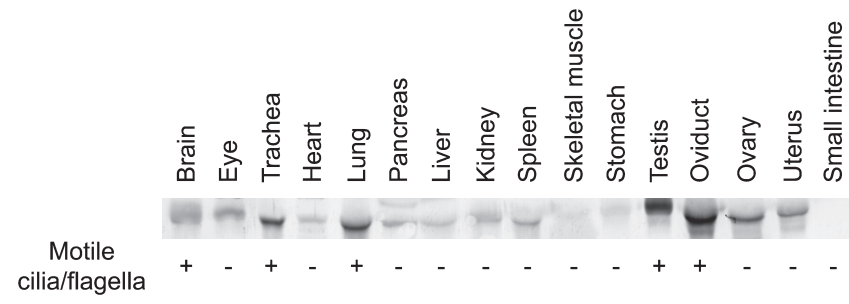

Fig. 2. NDK7 protein is contained preferentially in tissues with motile axonemes. Western blot analyses of mouse multiple tissues using an antimouse NDK7 polyclonal antibody show that NDK7 is present in various tissues but abundantly in tissues with motile axonemes such as trachea, lung, testis and oviduct. Tissues that have motile cilia or flagella are marked with "+" and those that lack them with "-".

elegans, an organism that has only sensory cilia. Domain analyses predicted that all NDK7 homologues have a similar domain composition (DM10-NDPk7A-NDPk7B) (Fig. 1a). The NDK7-like sequences in Tetrahymena and zebra fish have additional functional domains, a V-type ATPase $116 \mathrm{kDa}$ subunit family domain and a truncated Peptidase C19B domain, respectively (Fig. 1b).

\section{NDK 7 is preferentially expressed in tissues with motile axonemes in mouse}

The expression of the NDK7 protein was examined in various mouse tissues. First, I prepared purified recombinant of mouse NDK7 (mNDK7) using sequential steps (Ikeda, 2008; see Materials and Methods) and obtained an antimNDK7 polyclonal antibody. This antiserum was subsequently affinity-purified using the antigen. Western blot analyses using this antibody showed that mNDK 7 is present abundantly in tissues that contain motile axonemes, including trachea, lung, testis and oviduct, while weak expression was detected nearly ubiquitously (Fig. 2). These results suggest that NDK7 is associated with motile cilia/flagella.

\section{NDK7 localizes along the core part of flagella in mouse sperm but exclusively in the cell bodies in tracheal epithelia}

To determine the localization of NDK7 in mouse sperm and tracheal epithelia, indirect immunofluorescence microscopy was performed. The affinity-purified antiserum was highly specific for NDK7 protein in respective tissues (Fig. 3a). Indirect immunofluorescence microscopy of mouse sperm showed that mNDK7 localizes along the entire length of the TritonX-100-insoluble fraction and in the head (prominently at the post-acrosomal region) (Fig. 3b). An antibody against the Chlamydomonas NDK7 (cNDK7) was also raised to examine its localization. This antibody detected a faint $260 \mathrm{kDa}$ band in addition to NDK7 in Western blot of axonemes. When used in immunofluorescence microscopy, it strongly stained the basal $1-2 \mu \mathrm{m}$ segment as well as the entire axoneme. The staining at the base is most likely due to the presence of the $260 \mathrm{kDa}$ protein, as shown by the staining with its specific antibody (Haru-aki Yanagisawa, unpublished result). Thus, although true localization of cNDK 7 must be studied with a more specific antibody, it is likely that cNDK7 is present over the entire length of the axoneme. Despite such limitations in immunolocalization, the presence of NDK7 in the Chlamydomonas axoneme is clearly shown by Western blot (Fig. 3c). Previous proteomic and genome-wide transcriptional studies of Chlamydomonas also suggested this protein in the flagella (Pazour et al., 2005; Stolc et al., 2005). These observations, together with in silico (Fig. 1) and expression (Fig. 2) analyses, suggest that NDK7 is an axonemal protein conserved among eukaryotes. Unexpectedly, however, NDK7 was not detected in the ciliary axonemes in tracheal epithelia; instead, it is localized in the cell bodies. This suggests that the axonemal localization of this protein depends on the cell type (Fig. 3b).

\section{NDK7 directly binds to microtubules in vitro}

The localization pattern of the NDK7 proteins in mouse sperm (Fig. 3) raised a possibility that NDK7 might bind to microtubules. To test this possibility, co-sedimentation assays was carried out using taxol-stabilized microtubules polymerized from porcine brain tubulin and a purified mNDK7 recombinant. As shown in Fig. 4a, mNDK7 coprecipitated with microtubules, suggesting that mNDK7 directly binds to microtubules. The binding constant estimated by quantitative analyses is $1.1 \times 10^{5} \mathrm{M}^{-1}$ (Fig. 4b). Binding of NDK7 to microtubules was also observed with the Chlamydomonas homologue (data not shown). These findings suggest that the microtubule-binding is a basic property of NDK7 that is conserved among eukaryotes.

\section{Discussion}

The present study showed that NDK7 is widely conserved in eukaryotes with motile axonemes (Fig. 1). This suggests that NDK7 plays essential roles for normal motility of the eukaryotic axonemes. Western blot analyses showed that NDK7 is contained preferentially in tissues with motile cilia/flagella in mouse (Fig. 2), and indirect immunofluorescence microscopy of mouse sperm demonstrated that NDK7 is localized along the flagellar core part, possibly the axoneme (Fig. 3). These observations also support the idea that NDK7 is essential for axonemal motility. In fact, a recent study showed that the knock out of this gene in mouse led to situs inversus and other deficiencies characteristic of ciliopathy, possibly due to defects in ciliary motility (Vogel et al., 2010). A blast search identified a Tetrahymena sequence that contains a subunit of a V-type ATPase 
a

\begin{tabular}{cc}
\multicolumn{2}{c}{ Mouse } \\
\hline Sperm & Tracheal epithelia \\
$(\mathrm{kDa})$ & -150 \\
-150 & -75 \\
-75 & -50 \\
-50 & -37 \\
-37 & -25 \\
-25 & \\
-20 & -15
\end{tabular}

C

Chlamydomonas

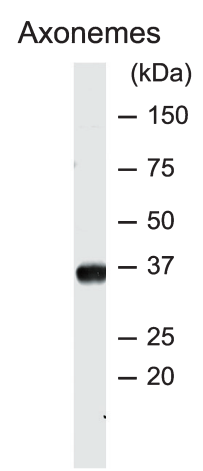

b

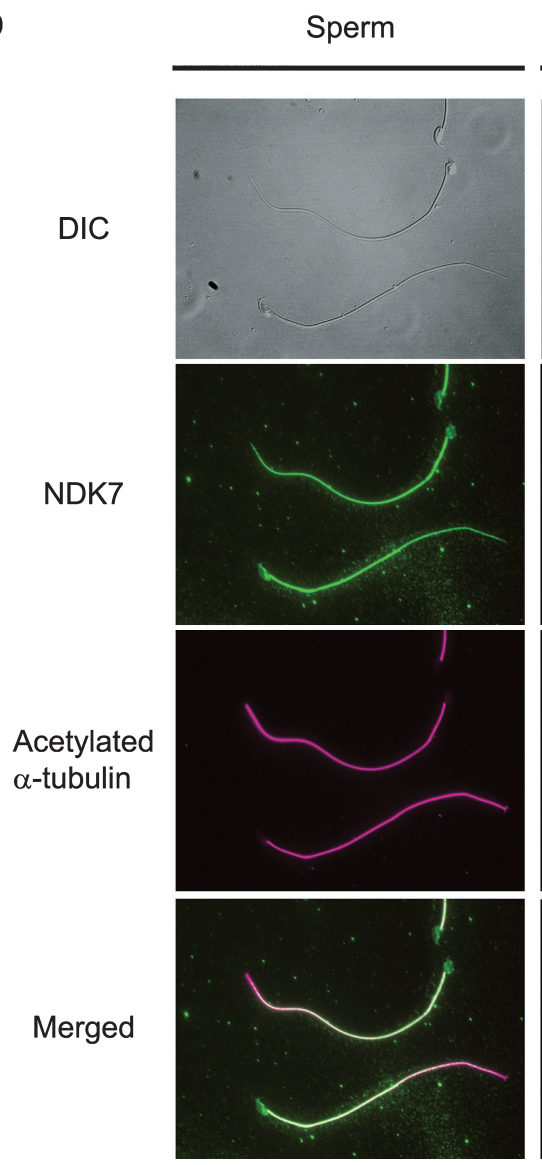

Tracheal epithelial cells
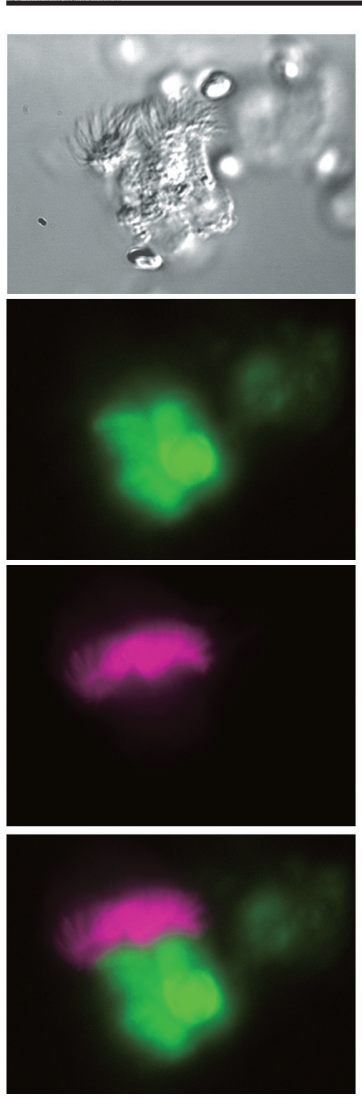

DIC

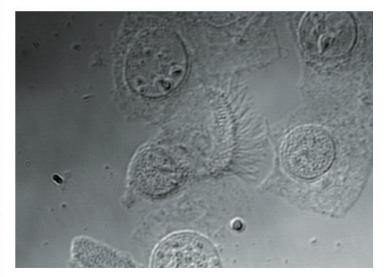

Efhc1

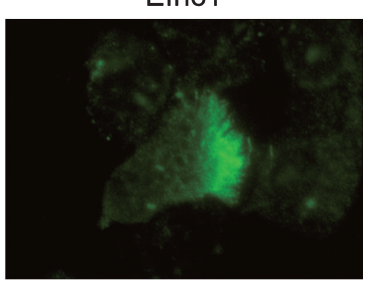

Fig. 3. NDK7 localizes along the entire length of the core part of flagella in mouse sperm but exclusively in the cell bodies in tracheal epithelial cells. (a) Specificity of the anti-mNDK7 antibody. Western analyses of mouse sperm and tracheal epithelial cells using the polyclonal antibody against mNDK7 show that the antibody specifically reacted with its antigen as single bands. (b) Indirect immunofluorescence microscopy using the NDK7 antibody. The signals are detected along the TritonX-100-insoluble fraction of mouse sperm flagella as well as in the head (prominently at the post-acrosomal region). In contrast, no signal is found in the ciliary region; instead it is found in the cell bodies in tracheal epithelial cells. Micrographs of tracheal epithelia stained with an antiEfhc1 antibody are reprinted with coloring (Ikeda et al., 2005). (c) Western analysis of Chlamydomonas axonemes using an anti-Chlamydomonas NDK7 antibody. 
a

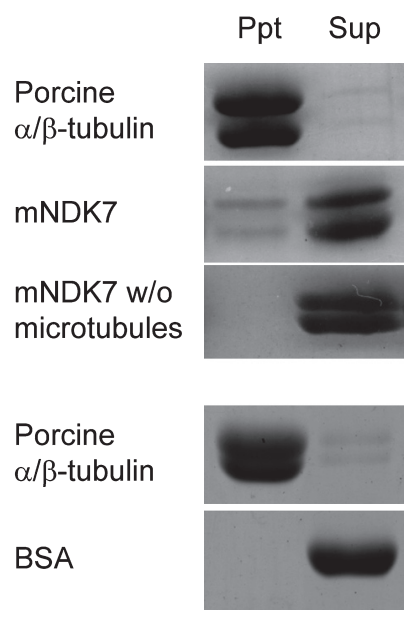

b

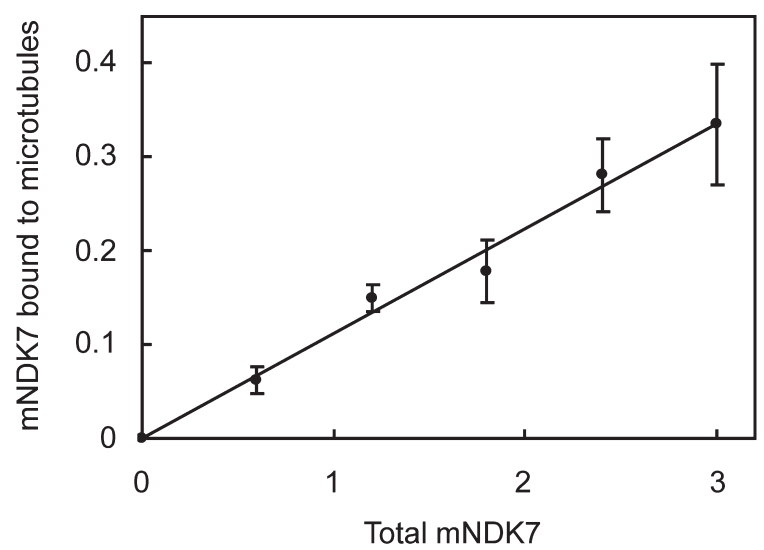

Fig. 4. NDK7 directly binds to microtubules in vitro. Co-sedimentation assays using purified recombinant mouse NDK7 protein and taxol-stabilized microtubules that were polymerized from porcine brain tubulin. SDS-PAGE analyses of the precipitated (Ppt) and the supernatant (Sup) fractions show that NDK7 directly binds to microtubules. (b) Quantitative analysis of mNDK7-microtubule interaction. A constant amount of taxol-stabilized microtubules were mixed with various amounts of recombinant mNDK7 and centrifuged. Quantities of total vs. precipitated NDK7 recombinants are plotted. Data for a given set of conditions were those averaged from three experiments. Bars, standard deviations.

domain connected to an NDK7-like sequence (DM10NDPk7A-NDPk7B) (Fig. 1b). Together, these observations suggest that NDK7 functions in some nucleotide metabolism related to axonemal functions, for which NDPk7A and NDPk7B domains may be responsible.

Unexpectedly, however, no NDK7 signal was detected in the ciliary region in tracheal epithelial cells (Fig. 3) while strong expression was detected in the cell body (Fig. 2 and Fig. 3). The NDK7 molecules in the tracheal cell may play a role in ciliary motility in an indirect manner. Localization of NDK7 in other tissues remains an interesting subject of future studies. The DM10 domain is proposed to act as an axoneme localization signal (King, 2006) because EFHC1/ Rib72/myoclonin1, another protein that contains DM10 domain, is associated with ciliary/flagellar axonemes (PatelKing et al., 2002; Ikeda et al., 2003; Ikeda et al., 2005; King, 2006; Suzuki et al., 2008). However, the result presented here suggests that the presence of the DM10 domain is not sufficient for axonemal localization.

The diffuse distribution of NDK7 in tracheal epithelia suggests that NDK7 might not always colocalize with microtubules in vivo (Fig. 3b). Nevertheless, an in vitro experiment in this study indicates a direct microtubulebinding property of NDK7, a property shared by NDK8 and NDK9 (Fig. 4) (Duriez et al., 2007; Sadek et al., 2003). Western blot analysis also showed that NDK7 is expressed at low levels in a variety of tissues (Fig. 3). This suggests that NDK7 is involved in some basic cellular functions in addition to cilia/flagella-specific functions. In fact, highlevel expression of NDK7 has been implicated in tumor development in organs that do not have motile cilia/flagella
(Seifert et al., 2005). The microtubule-binding properties of NDK7 may well underlie the function of NDK7 in a wide range of cell types and intracellular locations.

Acknowledgments. The author would like to thank Professor Ritsu Kamiya (University of Tokyo) for encouragement and critically reading the manuscript; Dr. Toshiki Yagi (University of Tokyo) for technical help in protein purification; Mr. Soh Nishio (University of Tokyo) for help in tubulin preparation and anti-Chlamydomonas NDK7 antibody production; and Dr. Haru-aki Yanagisawa (University of Tokyo) for providing detailed information on specificity of the anti-Chlamydomonas antibody. This study was supported in part by the Research Fellowship of the Japan Society for the Promotion of Science (JSPS) for Young Scientists.

\section{References}

Boissan, M., Dabernat, S., Peuchant, E., Schlattner, U., Lascu, I., and Lacombe, M.L. 2009. The mammalian Nm23/NDPK family: from metastasis control to cilia movement. Mol. Cell. Biochem., 329: 51-62.

Chang, C.L., Zhu, X.X., Thoraval, D.H., Ungar, D., Rawwas, J., Hora, N., Strahler, J.R., Hanash, S.M., and Radany, E. 1994. Nm23-H1 mutation in neuroblastoma. Nature, 370: 335-336.

Duriez, B., Duquesnoy, P., Escudier, E., Bridoux, A.M., Escalier, D., Rayet, I., Marcos, E., Vojtek, A.M., Bercher, J.F., and Amselem, S. 2007. A common variant in combination with a nonsense mutation in a member of the thioredoxin family causes primary ciliary dyskinesia. Proc. Natl. Acad. Sci. USA, 104: 3336-3341.

Gorman, D.S. and Levine, R.P. 1965. Cytochrome $f$ and plastocyanin: their sequence in the photosynthetic electron transport chain of Chlamydomonas reinhardi. Proc. Natl. Acad. Sci. USA, 54: 1665-1669.

Hoppe, P.C. 1975. Fertilizing ability of mouse sperm from different epididymal regions and after washing and centrifugation. J. Exp. Zool., 192: 219-222.

Ikeda, K., Brown, J.A., Yagi, T., Norrander, J.M., Hirono, M., Eccleston, E., Kamiya, R., and Linck, R.W. 2003. Rib72, a conserved protein asso- 
ciated with the ribbon compartment of flagellar A-microtubules and potentially involved in the linkage between outer doublet microtubules. J. Biol. Chem., 278: 7725-7734.

Ikeda, T., Ikeda, K., Enomoto, M., Park, M.K., Hirono, M., and Kamiya, R. 2005. The mouse ortholog of EFHC1 implicated in juvenile myoclonic epilepsy is an axonemal protein widely conserved among organisms with motile cilia and flagella. FEBS Lett., 579: 819-822.

Ikeda, T. 2008. Parkin-co-regulated gene $(P A C R G)$ product interacts with tubulin and microtubules. FEBS Lett., 582: 1413-1418.

King, S.M. 2006. Axonemal protofilament ribbons, DM10 domains, and the link to juvenile myoclonic epilepsy. Cell Motil. Cytoskeleton, 63: $245-253$.

Lacombe, M.L., Milon, L., Munier, A., Mehus, J.G., and Lambeth, D.O. 2000. The human Nm23/nucleoside diphosphate kinases. J. Bioenerg. Biomembr., 32: 247-258.

Leone, A., Flatow, U., King, C.R., Sandeen, M.A., Margulies, I.M., Liotta, L.A., and Steeg, P.S. 1991. Reduced tumor incidence, metastatic potential, and cytokine responsiveness of nm23-transfected melanoma cells. Cell, 65: 25-35.

Ma, D., Xing, Z., Liu, B., Pedigo, N.G., Zimmer, S.G., Bai, Z., Postel, E.H., and Kaetzel, D.M. 2002. NM23-H1 and NM23-H2 repress transcriptional activities of nuclease-hypersensitive elements in the platelet-derived growth factor-A promoter. J. Biol. Chem., 277: 15601567.

Ma, D., McCorkle, J.R., and Kaetzel, D.M. 2004. The metastasis suppressor NM23-H1 possesses 3'-5' exonuclease activity. J. Biol. Chem., 279: 18073-18084.

MacDonald, N.J., Freije, J.M., Stracke, M.L., Manrow, R.E., and Steeg, P.S. 1996. Site-directed mutagenesis of $n m 23-H 1$. Mutation of proline 96 or serine 120 abrogates its motility inhibitory activity upon transfection into human breast carcinoma cells. J. Biol. Chem., 271: 2510725116.

Miranda-Vizuete, A., Tsang, K., Yu, Y., Jiménez, A., Pelto-Huikko, M., Flickinger, C.J., Sutovsky, P., and Oko, R. 2003. Cloning and developmental analysis of murid spermatid-specific thioredoxin-2 (SPTRX-2), a novel sperm fibrous sheath protein and autoantigen. J. Biol. Chem., 278: 44874-44885.

Munier, A., Serres, C., Kann, M.L., Boissan, M., Lesaffre, C., Capeau, J., Fouquet, J.P., and Lacombe, M.L. 2003. Nm23/NDP kinases in human male germ cells: role in spermiogenesis and sperm motility? Exp. Cell Res., 289: 295-306.

Nonaka, S., Tanaka, Y., Okada, Y., Takeda, S., Harada, A., Kanai, Y., Kido, M., and Hirokawa, N. 1998. Randomization of left-right asymmetry due to loss of nodal cilia generating leftward flow of extraembryonic fluid in mice lacking KIF3B motor protein. Cell, 95: 829-837.

Olmsted, J.B. 1981. Affinity purification of antibodies from diazotized paper blots of heterogeneous protein samples. J. Biol. Chem., 256 : 11955-11957.

Patel-King, R.S., Benashski, S.E., and King, S.M. 2002. A bipartite $\mathrm{Ca}^{2+}$ regulated nucleoside-diphosphate kinase system within the Chlamydomonas flagellum. The regulatory subunit p72. J. Biol. Chem., 277: 34271-34279.

Patel-King, R.S., Gorbatyuk, O., Takebe, S., and King, S.M. 2004. Flagellar radial spokes contain a $\mathrm{Ca}^{2+}$-stimulated nucleoside diphosphate kinase. Mol. Biol. Cell, 15: 3891-3902.

Pazour, G.J., Agrin, N., Leszyk, J., and Witman, G.B. 2005. Proteomic analysis of a eukaryotic cilium. J. Cell Biol., 170: 103-113.

Piperno, G. and Fuller, M.T. 1985. Monoclonal antibodies specific for an acetylated form of $\alpha$-tubulin recognize the antigen in cilia and flagella from a variety of organisms. J. Cell Biol., 101: 2085-2094.

Postel, E.H., Abramczyk, B.M., Levit, M.N., and Kyin, S. 2000. Catalysis of DNA cleavage and nucleoside triphosphate synthesis by NM23-H2/ NDP kinase share an active site that implies a DNA repair function. Proc. Natl. Acad. Sci. USA, 97: 14194-14199.

Sadek, C.M., Damdimopoulos, A.E., Pelto-Huikko, M., Gustafsson, J.A., Spyrou, G., and Miranda-Vizuete, A. 2001. Sptrx-2, a fusion protein composed of one thioredoxin and three tandemly repeated NDP-kinase domains is expressed in human testis germ cells. Genes Cells, 6: 10771090

Sadek, C.M., Jiménez, A., Damdimopoulos, A.E., Kieselbach, T., Nord, M., Gustafsson, J.A., Spyrou, G., Davis, E.C., Oko, R., van der Hoorn, F.A., and Miranda-Vizuete, A. 2003. Characterization of human thioredoxin-like 2. A novel microtubule-binding thioredoxin expressed predominantly in the cilia of lung airway epithelium and spermatid manchette and axoneme. J. Biol. Chem., 278: 13133-13142.

Seifert, M., Welter, C., Mehraein, Y., and Seitz, G. 2005. Expression of the nm23 homologues nm23-H4, nm23-H6, and nm23-H7 in human gastric and colon cancer. J. Pathol., 205: 623-632.

Shelanski, M.L., Gaskin, F., and Cantor, C.R. 1973. Microtubule assembly in the absence of added nucleotides. Proc. Natl. Acad. Sci. USA, 70: $765-768$

Steeg, P.S., Bevilacqua, G., Kopper, L., Thorgeirsson, U.P., Talmadge, J.E., Liotta, L.A., and Sobel, M.E. 1988. Evidence for a novel gene associated with low tumor metastatic potential. J. Natl. Cancer Inst., 80: 200-204.

Stolc, V., Samanta, M.P., Tongprasit, W., and Marshall, W.F. 2005. Genome-wide transcriptional analysis of flagellar regeneration in Chlamydomonas reinhardtii identifies orthologs of ciliary disease genes. Proc. Natl. Acad. Sci. USA, 102: 3703-3707.

Suzuki, T., Inoue, I., Yamagata, T., Morita, N., Furuichi, T., and Yamakawa, K. 2008. Sequential expression of Efhc1/myoclonin1 in choroid plexus and ependymal cell cilia. Biochem. Biophys. Res. Commun., 367: 226-233.

Tompson, J.D., Higgins, D.G., and Gibson, T.J. 1994. CLUSTAL W: improving the sensitivity of progressive multiple sequence alignment through sequence weighting, position-specific gap penalties and weight matrix choice. Nucleic Acids Res., 22: 4673-4680.

Towbin, H., Staehelin, T., and Gordon, J. 1979. Electrophoretic transfer of proteins from polyacrylamide gels to nitrocellulose sheets: procedure and some applications. Proc. Natl. Acad. Sci. USA, 76: 4350-4354.

Tsuiki, H., Nitta, M., Furuya, A., Hanai, N., Fujiwara, T., Inagaki, M., Kochi, M., Ushio, Y., Saya, H., and Nakamura, H. 1999. A novel human nucleoside diphosphate (NDP) kinase, Nm23-H6, localizes in mitochondria and affects cytokinesis. J. Cell Biochem., 76: 254-269.

Vogel, P., Read, R., Hansen, G.M., Freay, L.C., Zambrowicz, B.P., and Sands, A.T. 2010. Situs inversus in $\mathrm{Dpcd} / \mathrm{Poll}^{-/-}, \mathrm{Nme}^{7-/}$, and $\mathrm{Pkdll1^{-/ }}$ mice. Vet. Pathol., 47: 120-131.

Witman, G.B., Carlson, K., and Rosenbaum, J.L. 1972. Chlamydomonas flagella. II. The distribution of tubulins 1 and 2 in the outer doublet microtubules. J. Cell Biol., 54: 540-555.

Yoon, J.H., Singh, P., Lee, D.H., Qui, J., Cai, S., O'Connor, T.R., Chen, Y., Shen, B., and Pfeifer, G.P. 2005. Characterization of the $3^{\prime} \rightarrow 5^{\prime}$ exonuclease activity found in human nucleoside diphosphate kinase 1 (NDK1) and several of its homologues. Biochemistry, 44: 15774-15786.

(Received for publication, August 21, 2009, accepted, February 18, 2010 and published online, March 10, 2010) 